To appear in the Oxford Encyclopedia of Linguistics (final version)

\title{
Natural Language Ontology
}

\author{
Friederike Moltmann \\ CNRS-IHPST and NYU
}

October 2016

\section{Summary}

Natural language ontology is a branch of both metaphysics and linguistics semantic. Its aim is to uncover the ontological categories, notions, and structures that are implicit in the use of natural language, that is, the ontology that a speaker accepts when using a language. Natural language ontology is part of descriptive metaphysics' to use Strawson's term or 'naïve metaphysics' to use Fine's term, that is, the metaphysics of appearances as opposed to foundational metaphysics, whose interest is in what there really is.

What sorts of entities natural language involves is closely linked to compositional semantics, namely what the contribution of occurrences of expressions in a sentence is taken to be. Most importantly entities play a role as semantic values of referential terms, but also as implicit arguments of predicates, and as parameters of evaluation.

Natural language appears to involve a particularly rich ontology of abstract, minor, derivative, and merely intentional objects, an ontology many philosophers are not willing to accept. At the same time a serious investigation of the linguistic facts often reveals that natural language does not in fact involve the sort of ontology that philosophers had assumed it does.

Natural language ontology not only concerns with the categories of entities that natural language commits itself to, but also with various metaphysical notions, for example the relation of part-whole, causation, material constitution, notions of existence, plurality and unity, and the mass-count distinction.

An important question regarding natural language ontology is what linguistic data it should take into account. Looking at the sorts of data that researchers that practice natural language ontology have in fact taken into account makes clear that it is only presuppositions, not assertions that reflect the ontology implicit in natural language.

The ontology of language may be distinctive in that it may in part be driven specifically by language or the use of it in a discourse. Pleonastic entities, discourse referents conceived of as entities of a sort, and an information-based notion of part structure involved in the semantics of plurals and mass nouns would be examples. Finally, there is the question of the universality of the ontology of natural language. Certainly the same sort of reasoning should apply to consider it universal, in a suitable sense, as has been applied for the case of (generative) syntax.

\section{Keywords}

Ontology, referential NP, abstract objects, events, tropes, implicit arguments, propositions 


\section{Natural language ontology: what it is and what issues it raises}

It has long been recognized that natural language appears to involve its own ontology. That is, there are ontological categories, notions, and structures that appear to be reflected in the semantics of various relevant sorts of natural language expressions and constructions. This ontology may be quite different from the one that a philosopher may be willing to accept -and even an 'ordinary' speaker when reflecting upon what there is. In fact, natural language appears to display a wealth of referential terms, quantifiers, or other expressions involving abstract, minor, or derivative entities such as properties, propositions, tropes (that is, particularized properties), numbers, degrees, events, facts, worlds or situations, intentional objects, and variable objects, entities which all have been considered problematic ontologically at one point or another. Natural language thus appears to involve a particularly rich ontology of various types of philosophically controversial entities.

The fact that natural language appears to involve such a wealth of controversial entities has led a number of philosophers to reject natural language as a guide to 'real' metaphysics or the ontology of what there really is. There are also philosophers, though, throughout the history of philosophy, who have appealed to natural language in support of one or another metaphysical view, arguing that particular ontological notions are implicit in language itself, and thus the way we commonly think. Aristotle has appealed to natural language at times and more systematically so medieval philosophers, especially in the Aristotelian tradition, such as Ockham and Aquinus. Appeal to natural language was also important in early and not so early analytic philosophy, as in the work of Frege, Twardowski, Austin, Vendler, Strawson, and Davidson, with a greater or lesser degree of systematicity. More recently, going along with the development of contemporary linguistic semantics, appeal to metaphysical notions reflected in natural language has not only been made in support of particular philosophical arguments but also just in the interest in uncovering the ontology involved in the semantics of natural language. Engaging in such a project then is engaging in natural language ontology, as a branch of both linguistic semantics and metaphysics.

Entities play various sorts of roles in the semantic structure of natural language, given various sorts of semantic theories about relevant constructions or expressions. Most importantly, entities play a role as semantic values of referential terms, terms that characteristically can support anaphora and be replaced by ordinary quantificational NPs. But 
entities may also play a semantic role as implicit arguments of predicates (while not being semantic values of referential terms), as contextual parameters of evaluation, and as truthmakers. What entities are taken to play a role in the semantics of natural language play a role in the semantics of natural language depends very much on the way the contribution of occurrences of expressions to the composition of the meaning of the sentence is conceived. Thus, generally the contribution of NPs acting as referential terms is taken to be that of standing for an object and the role of expressions acting as predicates to take objects as arguments and to yield truth values. The ontology of natural language is thus intimately linked to compositional semantics, the semantically relevant syntactic roles of expressions in a sentences. Here is a brief overview of the sorts of entities of the more controversial types that have been argued to be part of the ontology of natural language.

Properties have long been considered taking a central stage in the ontology of natural language, most obviously as referents of bare nominalizations of adjectives such as wisdom (as in Socrates has wisdom), of explicit property-referring terms (the property of wisdom), or of gerunds or infinitival clauses (being wise, to be wise). ${ }^{1}$ Properties, though, have also been considered the semantic values of predicative complements, and of the quantifiers and pronouns that can take their place, as in the valid inference from (1a) to (1b) and the possibility of anaphoric reference in (1c):

(1) a. Socrates is wise.

b. Socrates is something.

c. Plato is that too.

Also 'minor' or ontologically dependent entities such as events and tropes (particularized properties) have been regarded part of the ontology of natural language.

Events are widely considered playing a central role in semantics ever since Davidson's (1967) seminal paper. Events obviously play the role of semantic values of nouns such as laughter, walk, and war. In addition, it has become a standard view in linguistic semantics following Davidson (1967) that verbs take events as implicit arguments, with adverbial modifiers acting as predicates of such events. Thus the verb walk as below will describe a two-place relation between events of walking and agents and slowly will act as a predicate of an event argument the sentence existentially quantifiers over:.

\footnotetext{
${ }^{1}$ For the view that gerunds and infinitival clauses refer to properties see Chierchia/Turner (1988).
} 
(2) a. John walked slowly.

b. $\exists$ e(walk(e, John) \& slowly(e))

c. John's walk was slow.

The role of adverbial modifiers to act as predicates of the event argument is reflected in the applicability of the corresponding adjectives to event nominalizations, as in (2c).

Tropes, for example Socrates' wisdom as opposed to wisdom in general, are particularized properties, manifestations of properties in individuals. Socrates' wisdom thus is the particular manifestation of wisdom in Socrates and as such distinct from the wisdom of Plato. While the term 'trope' is a fairly recent (and somewhat misleading) term, introduced by Williams (1953), tropes had played an important role already as 'accidents' or 'modes' in Aristotelian metaphysics. $^{23}$ They certainly have been considered part of the ontology of language much earlier than events, especially in medieval language-oriented philosophy (Aquinus, Ockham). Tropes have traditionally been considered the semantic values of referential NPs formed with adjective nominalizations such as Socrates' wisdom or John's happiness, or the redness of the apple (Strawson 1959, Woltersdorff 1970, Moltmann 2004, 2013b, Chap 2).

Just as for Davidson's semantics of events, modifiers of adjectives motivate the view that tropes act as implicit arguments of adjectives (Moltmann 2009, 2013b). Modifiers of adjectives, at least to an extent, also occur as predicates of the corresponding relevant tropereferring term:

(3) a. Socrates is extremely wise.

b. Socrates' wisdom is extreme.

This means that wise describes a relation between wisdom tropes (manifestations of wisdom) and agents. Alternatively, degrees have been considered implicit arguments of adjectives, for the purpose of the semantics of comparatives and various measure-related constructions (two meters tall, extremely happy etc) (Cresswell 1977).

Also numbers have been considered part of the ontology of natural language. Most prominently, Frege (1884) had argued that natural language permits reference to numbers as objects, by appealing to statements such as (4):

\footnotetext{
${ }^{2}$ They continue to play the same sort of role in the work of Neo-Aristotelians such as Lowe (2006).

3 Tropes are also called 'abstract particulars' in Campbell (1990) and 'cases' in Woltersdorff (1970).
} 
(4) The number of planets is eight.

Frege took (4) to be an identity statement involving reference to numbers with both the subject term and the postcopula number word (an assumption that is problematic, as will be discussed later).

Finally, it is a common view that propositions as abstract mind- and language-independent objects that are truth bearers play a central role in the semantics of natural language (Stalnaker 1984, Schiffer 2003). As the meanings of sentences, propositions are also meant to act as the semantic values of that-clauses and thus as arguments of predicates embedding that-clauses, such as attitude verbs as in (5a). Again quantifiers such as something as in (5b) and pronouns of the sort of that as in (5c), when they take the place of clausal complements seem to take propositions as semantic values:

(5) a. John thinks that it is raining.

b. John thinks something.

c. Bill thinks that too.

There are further proposition-like entities that seem to be part of the ontology of natural language, in particular non-worldly facts (as referents of terms of the sort the fact that $\mathrm{S}$ or factive that-clauses) (Fine 1982b, Asher 1993, Moltmann 2013b, Zucchi 1983).

Natural language also appears to involve variable objects, as the semantic values of terms of the sort the paper John needs to write, terms whose referential status appears reflected in their ability to support anaphora (Moltmann 2013b, to appear b): ${ }^{4}$

(6) The paper John needs to write must be 20 pages long. It cannot be any shorter or longer.

Variable objects would be entities that have manifestations as ordinary objects in particular situations -- in the case of (6), situations satisfying John's need.

\footnotetext{
${ }^{44}$ Anaphoric reference is also available relating to the indefinite in the discourse below::

(i) John needs to write a paper. It must be 20 pages long.

This, however, is a case of modal subordination where a paper is not a referential term, but rather introduces into a subordinate modal contex, a discourse referent which can then serve as antecedent of a subsequent pronoun that occurs in the same modal context, at least on the standard analysis (see Section 8). In (6), by contrast, the definite stands for an object that incorporates the modal element, a variable object.
} 
In addition to the various ontological categories of abstract or derivative entities that natural language appears to permit reference to, natural language also seems to allow for terms to stand for merely intentional objects (of any categories), entities considered 'nonexistent' by the speaker. That is, natural language appears to reflect a Meinoningian view of there being objects that fail to exist (Parsons 1980, Salmon 1987, 1998, Fine 1982a, Priest 2005, Moltmann 2013a, 2016 a). Terms of the relevant sort may appear both in the subject position of negative existentials as in (7a) and in the object position of intentional verbs such as think as in (8a). In both positions, those terms allow for a replacement by pronouns and quantifiers as in $(7 \mathrm{~b}, \mathrm{c})$ and $(8 \mathrm{~b}, \mathrm{c})$, further supporting their referential status:

(7) a. The building described in the book does not exist.

b. It has never existed.

c. A building described in the book does not exist.

(8) a. John thought about a building described in the book.

b. John thought about it for a long time.

c. John thought about some building.

Intentional objects as 'nonexistent' objects are considered particularly problematic (Inwagen 2001).

Natural language also appears to allow for reference to plural entities, without imposing particular restrictions on their mereological composition, with the use of definite plurals and conjunctions (the things in the room, Obama and the Eiffeltower etc) (Link 1983). However, there are alternative views according to which such terms refer plurally to several individuals at once, rather than a single plural individual (Yi 2005, 2006, Oliver/Smiley 2013, Moltmann 2016 b).

In addition for entities acting as semantic values of natural language expressions, entities may also be involved in the semantic structure of sentences as parameters that help determine the truth value of sentences or the proposition a sentence expresses. In particular, times and possible worlds (or perhaps situations, partial possible worlds) are generally taken to play that role. This goes along with the view that modals and tense act semantically as operators that may shift those parameter of evaluation.

Clearly, given such a range of entities, the ontology displayed by natural language differs from the sort of ontology that a philosopher may be willing to accept. But it may also differ from the ontology an 'ordinary' speaker of the language may be willing to accept when 
reflecting upon what there really is. An ordinary speaker may hold various views when thinking about what sorts of things there are, what their general characteristics are and how they relate to each other, and may endorse or reject various ontological statements as a result of such reflections. It is therefore essential that natural language ontology make a distinction between statements based on philosophical reflection and linguistic data that are part of a nonphilosophical use of language. Natural language ontology concerns itself with the ontological categories and structures implicit in 'ordinary' statements of a nonphilosophical discourse, not those that form part of the content of philosophical or quasi-philosophical assertions. It concerns itself with the ontological categories and structures a speaker accepts when using a language, not those a speaker accepts when engaging in some form of philosophical reflection.

Of course, this general distinction calls for more precise criteria that distinguish the two sorts of linguistic material: linguistic data that reflect the ontological categories and structures implicit in natural language and linguistic data manifesting a speaker's reflections. In particular it calls for criteria for characterizing the ontological categories and structures natural language involves and identifying what sorts of entities it is committed to. In the history of metaphysics, linguistic data have of course often been taken into account, during some periods more than others (in medieval metaphysics, for example, linguistic data played a crucial role, as they did in early analytic philosophy). But in general such data were used, somewhat arbitrarily and unsystematically, in support of general philosophical intuitions that may have had other sources of support as well.

Given the subject matter of natural language ontology, one may also ask what the value of natural language ontology should be since it does not concern itself with what there really is. This is an issue will be addressed both in the next section and in Section 7.

Natural language ontology not only concerns itself not only with the categories of objects that the semantics of natural language commits itself to. It also deals with metaphysical notions of various sorts, such as part-whole relations (Moltmann 1997, 1998), constitution (Fine 2003, King 2006), causation (Swanson 2012), (time- and space-relative) existence (Fine 2006, Moltmann 2013d), and existence of he past (the presentism debate) (Szabo 2007, Sider 2006). But natural language ontology also has its limits, in the sense that it does not bear on all sorts of issues in metaphysics. Topics that it does not bear on include the existence of god, personhood, free will, and what entities are more fundamental than others

It should also be added that it also reasonable that some topics in metaphysics are best be addressed jointly, by taking into account both what is reflected in natural language and purely 
philosophical or even other empirical considerations, for example questions in the ontology of the mind may benefit from taking into account both natural language and cognitive science.

\section{Ontology and metaphysics: some distinctions}

At this point few terminological and conceptual issues should be clarified regarding the project of natural language ontology.

First of all, the term 'natural language ontology' is generally used ambiguously, referring either to the discipline or its subject matter, the ontological categories, notions, and structures reflected in natural language. 'The ontology of natural language' tends to be used in the second sense. Throughout this paper, I will generally use the term 'natural language ontology' only, and in the first sense.

Second, there is a distinction generally made in philosophy between ontology and metaphysics. Given that distinction, ontology concerns itself only with what there is, whereas metaphysics also concerns itself with the nature of things. In view of that distinction, 'natural language metaphysics' would be a more appropriate term than 'natural language ontology'. However, the latter has established itself more widely and for that reason alone should better be the one to use. ${ }^{5}$

Third, it is important to distinguish different projects in metaphysics in order to allow natural language ontology to obtain its proper recognition. One distinction that has been made in the literature is Strawson's (1959) well-known distinction between descriptive and revisionary metaphysics by. As Strawson characterizes it, 'descriptive metaphysics' has as its aim to uncover our shared conceptual scheme, whereas revisionary aims to conceive of a better ontology than how we ordinarily conceive of things. Whereas descriptive metaphysics aims to develop an ontological theory that would be reflected in our common sense intuitions, revisionary metaphysics develops an ontological theory for a particular purpose (such as perhaps the development of scientific theories). Clearly, natural language ontology would fall under descriptive metaphysics, and in fact can be considered the pursuit of a particularly strict version of descriptive metaphysics, one that is entirely based on linguistically reflected intuitions.

\footnotetext{
${ }^{5}$ The term 'natural language metaphysics', though, is used by Emmon Bach in Bach (1986) and Chao/Bach (2011), papers that give an overview of various ontological categories generally posited in formal semantics at the time, without, however, relating to the philosophical traditions, issues, and debates.
} 
A somewhat different distinction has recently been made by Fine (to appear a), namely between 'naïve' metaphysics and 'foundational' metaphysics. Naïve metaphysics concerns itself with how things appear to be, without trying to address the question of what there really is. The latter is what foundational metaphysics aims to do. Foundational metaphysics, though, presupposes naïve metaphysics, whose notions it in fact should aim to explain in more fundamental terms, as Fine argues. Naïve metaphysics is the metaphysics of appearance, and as such should not be guided by considerations of foundational metaphysics, but rather foundational metaphysics relies on naïve metaphysics in order to do its foundational work.

Natural language ontology obviously is part of naïve metaphysics. But of course, it is not 'naïve' in the sense of concerning itself with what the ordinary person naively takes there to be. Rather, as part of the metaphysics of appearance, it deals with the ontological categories, notions, and structures that a deep and systematic analysis of language uncovers. ${ }^{6}$

\section{The ontology of natural language and the reflective ontology of speakers}

Philosophers that pursue natural language ontology either as a subject matter in itself or for the purpose of particular philosophical arguments generally follow a particular practice, making use of certain linguistic data but not others. That is, there are implicit assumptions regarding what sorts of data make a convincing case for an ontological notion to be reflected in natural language. Let us thus try to make more explicit the criteria that distinguish the linguistic data that would be indicative of the ontology of natural language from those that would be indicative, say, of the reflective ontology of speakers.

\subsection{Asserted and presupposed content: semantic selectional requirements}

One distinction that certainly plays a role is the distinction between assertions and presuppositions. Ontological generalizations that are presupposed by sentences 'ordinary' speakers use (that is, speakers when not engaging in philosophical debate) certainly qualify as a reflection of the ontology of natural language. By contrast, sentences that themselves make metaphysical assertions are hardly taken to be evidence for the ontology of natural language and in fact philosophers generally do not make use of such sentences when appealing to

\footnotetext{
${ }^{6}$ Fine (p.c.) also uses the term 'shallow metaphysics' instead of 'naïve metaphysics', perhaps a better choice when it comes to natural language ontology. 'Shallow metaphysics' is the term I use, following Fine (p.c.), in Moltmann (2014b) for the branch of the metaphysics that natural language ontology belongs to.
} 
natural language for the purpose of metaphysical arguments. Thus a statement such as (9a) would not be considered evidence for the distinctness of the categories of facts and events in the ontology of natural language, and so for the statements in (9b), (9c) and (9d):

(9) a. Facts are not events.

b. There are properties.

c. Numbers are objects.

d. There are events.

Statements of the sort in (9) would not be considered support for an ontological distinction between facts and events, for an ontological commitment to properties, for numbers being objects, or for an ontological commitment to events, as part of the ontology of natural language. Not even assertions regarding the ontological category of about particular objects, as below, could qualify:

(10) a. The fact that it is raining is not an event.

b. The property of being wise is a property.

c. The number two is a number.

$\mathrm{d}$. The rain is an event.

The statements in (10) would hardly be appealed to when arguing for a distinction between events and facts or for an ontological commitment to properties, numbers or events.

Let us contrast these examples with the sorts of statements that have actually been used to argue for natural language supporting an ontological distinction. Thus, contrasts such as those between (11a) and (11b) and between (12a) and (12b) have been used to argue for an ontological distinction between facts and events (Vendler 1967, Asher 1993):

(11) a. The rain lasted several days.

b. ??? The fact that it rained lasted several days.

(12) a. John watched the rain.

b. ??? John watched the fact that it rained.

Contrasts such as those between (13a) and (13b), between (14a) and (14b), and between (15a) and (15b) have been used to argue for a fundamental distinction between material 
objects and events with respect to how they relate to space and time (Hacker 1982, Cresswell 1986, Fine 2006, Moltmann 2013d):

(13) a. John's arrival took place yesterday.

b. ??? John's arrival existed yesterday.

(14) a. ??? The building took place last year.

b. The building existed last year.

(15) a. The party is tomorrow.

b. ??? The cake is tomorrow.

Contrasts such as between (16a) and (16b) and between (17a) and (17b) have been used in order to argue for an ontological distinction between actions and their (nonenduring) products (Twardowski 1911, Moltmann 2013b Chap 4, 2014b):

(16) a. John's claim is true.

b. ??? John's speech act is true.

(17) a. John kept / broke his promise.

b. ??? John kept / broke his speech act.

The reason why statements of the sort in (11) - (17) are considered relevant for natural language ontology is because such statements do not make metaphysical assertions, but rather carry metaphysical presuppositions, which here are conditions on the applicability of predicates to entities of particular ontological categories. Semantic selectional requirements or category restrictions imposed by predicates are one important source of data regarding the ontological categories reflected in natural language. ${ }^{7}$

\subsection{Identity statements and the trap of specificational sentences}

Another sort of sentence that is generally taken to be indicative of particular ontological categories being reflected in natural language is identity statements involving reference to instances of the category in question -- or rather what appear to be identity statements. Thus,

\footnotetext{
${ }^{7}$ For a recent discussion of category mistakes and a defense of a presuppositional account of them see Magidor (2013).
} 
Frege (1884) thought that statements such as (2) repeated below, would support the status of numbers as objects - in the ontology of natural language and, thus, as such:

(18) The number of planets is eight.

In this sentence, the number of planets a well as eight for Frege are referential terms, having the semantic function of standing for an object. It is significant that Frege did not cite sentences such $(9 \mathrm{c}, 10 \mathrm{c})$, which assert what for Frege (18) presupposes, namely that numbers are objects. In (18), the presupposition is not a selectional requirement of a predicate, though. Rather, for Frege, it is tied to two singular terms for numbers flanking the identity predicate.

Similar examples appear to be evidence for entities such as beliefs, promises, reasons, and facts being propositions, the semantic values of that clauses. Thus, the apparent identity statements below appear to show that what a that-clause stands for, a proposition, can be a belief (19a), a promise (19b), a reason (19c), or a fact (19d):

(19) a. John's belief is that he will return.

b. John's promise is that he will help Mary.

c. The reason why John left is that he wanted to avoid being interrogated.

$\mathrm{d}$. The fact John mentioned is that the meeting is over.

The examples in (19) are problematic, however, as support for the ontological views for which they have been used. Such sentences, as has been argued, are better not viewed as identity statements, but instead as so-called 'specificational sentences' (Higgins 1973, Romero 2005), that is, as being of the same type as sentences of the sort in (20):

(20) What John is is happy.

In specificational sentences, it is generally agreed, neither the subject nor the postcopula expression functions as a referential term. Rather than expressing the identity of objects, specificational sentences have been regarded as either expressing the identity of semantic values of a higher type or, more commonly as expressing question-answer relations, with the subject being a concealed question and the postcopula expression an elided answer. ${ }^{8}$ On the

\footnotetext{
${ }^{8}$ The first view, the Identity Theory, is due to Jacobson (1994), the second view, the Question-Answer Theory, to den Dikken et al. (2000).
} 
latter view, (18) would make a statement roughly of the sort 'how many planets are there there are eight planets' (Moltmann 2013a, b), (19a) of the sort 'what does John believe' John believes that he will return, (19b) of the sort 'what does John promise? - John promises that he will help Mary', (19c) of the sort 'why did John leave - John left in order not to be interrogated' (Pryor 2007), and (19d) of the sort 'what fact did John mention? - John mentioned the fact that the meeting was over'. This then makes sentences (19) compatible with the view that number words such as eight stand for plural properties rather than number objects (Moltmann 2013a), the view that beliefs are not propositions (but rather propositional attitudes or mental states, the common view in the philosophy of mind), that promises are not propositions (but products of illocutionary acts, Twardowski 1911, Moltmann 2013b Chap 4, 2014a), the view that that reasons are not propositions (Pryor 2007), and the view that facts are not (true) propositions (Vendler 1972, Fine 1982b, Asher 1993, Zucchi 1983).

\subsection{Reifying terms and the core-periphery distinction}

There are related subject-predicate sentences that appear to make the same point as the apparent identity statements in (18) and (19):

(21) a. Eight is a number that is divisible by two and four.

b. That he will return is a belief that John certainly has.

c. That he will help is a promise John frequently made.

d. That he wants to avoid being interrogated is not a reason for John to leave.

The sentences in (21) differ from the sentences in (10) in that their focus is on the material after the head noun and not the noun itself, which means that the sentences in (21) presupposes, rather than asserts, that the subject referent falls under the sortal.

There are good grounds for taking the predicate-initial sortal in (21) not to be an ordinary predicate, but a reifying device (Moltmann 2013b Chap. 6), the very same function it has in the examples in (22) or even more obviously those in (23):

(22) a. the number eight

b. John's belief that he will return

c. John's promise that he will help

d. the reason that he wants to avoid being interrogated 
(23) a. the concept horse

b. the truth value true

c. the property of wisdom

Reifying sortals as in (22) and in (23) serve not to attributing a property to an object, but to introduce a 'new' object on the basis of nonreferential linguistic (uses of) expressions (such as nouns, adjectives, or, arguably, that-clauses) (Moltmann 2013b, Chap. 6). Though reifying terms are part of English, they can be taken at best as evidence for certain types of objects playing a role in a derivative part of language, which tends to be used for a more or less philosophical sort of discourse. Reifying terms are generally not taken as a reflection of objects being part of the ontology of natural language. Frege, for example, did not appeal to them when arguing for numbers and truth values being objects.

This raises a more general issue for natural language ontology. Natural language generally can be extended with terms (reifying terms or proper names, for example) for various sorts of 'philosophical entities', which some philosophers may accept, but that one would not consider part of the implicit ontology of natural language, the ontology any speaker accepts when using the language. Such terms in a sense belong to the periphery of language, not the core of language. ${ }^{9}$ The ontology reflected in the periphery of a language needs to be distinguished from that reflected in its core, the ontology any speaker accepts when using the language:

\section{(24) Ontology and the Core-Periphery Distinction}

The ontology of natural language is reflected in the core of language, not its periphery.

Certainly, the periphery of language also has a semantics, and it also reflects an ontology, with its referential terms standing for entities of some sort. Using Fine's (to appear a) notion, this ontology would be part of the subject the metaphysics of 'appearance' and thus of naïve

\footnotetext{
${ }^{9}$ The terms core and periphery recall a different and important distinction that Chomsky (1986) made regarding the syntactic structure of languages. For Chomsky, the core of a language consist in what is determined by the (innate) Universal Grammar, its universal principles together with the way its parameters are set for that language, whereas the periphery consist in idiosyncratic rules unique to that language, rules added on in the historical development of the language. Chomsky's distinction does not in any way coincide with the present one. Clearly, the formation of new philosophical terms may take place entirely within what Chomsky would call the core of language, as is presumably the case for reifying terms.

One might speculate that the ontology associated with what I call of 'the core of language' forms part of Universal Grammar when supplemented by cognitive ontology, whereas the ontology reflected in the periphery in my sense forms part of the periphery of language in Chomsky's sense. However, ontology itself may consist not so much in a set of categories, but rather in conditions for generating objects from given ones (for examples principles of abstraction discussed in Section 6), and the so generated objects may be part of what is reflected in the periphery in my sense.
} 
metaphysics - and that even if the extension of the language concerns in fact terms of foundational metaphysics.

\section{Criteria of ontological commitment in the core of language}

The issue of the ontological commitments of natural language is the issue of what categories of objects are part of the ontology of natural language and thus play a role in the semantic structure of natural language sentences.

There are various ways for entities to play a role in the semantics of natural language. Clearly, the most prominent one and the one the philosophical literature generally focuses on is captured by Frege's criterion for objecthood. According to that criterion, an object is what a referential term may stand for. Frege's criterion of objecthood goes along with his context principle, which ties the syntactic role of an expression to its semantic contribution to the composition of the meaning of the sentence.

The applicability of Frege's criterion obviously hinges on the notion of a referential term, as a syntactic role of occurrences of expressions in natural language sentences. What characterizes the occurrence of an expression in a sentence as a referential term? Note that not all NPs can act as referential terms since NPs can occur also as predicative complements and as complements of intensional transitive verbs such as need and look for. There is no agreement how exactly to characterize that syntactic role of an occurrence of an expression acting as a referential term. It is mainly philosophers, including Frege, that have proposed various criteria for referential terms, such as the ability of flanking the identity predicate, the ability of supporting anaphora, and the ability of being replaceable by a quantifier (Hale 1987). ${ }^{10}$ Clearly the role of an expression to act as a referential term is central for natural language ontology, and more generally the view that the ontology of natural language systematically relates to syntactic structure. The criteria for referential terms that have been proposed are not unproblematic, however.

First of all, not all sorts of quantifiers that are able to replace an occurrence of an expression in a sentence are indicative of that expression acting as a referential term. In fact, there is a class of special quantifiers that characteristically are able to replace nonreferential occurrences of expressions. In English, this class consists of quantifiers like something,

\footnotetext{
${ }^{10}$ Quine (1948) took quantification to be the criterion of ontological commitment, with his statement 'to be is to be the value of a bound variable'.
} 
everything, nothing, and several things. They can replace predicative complements and complements of intensional transitive verbs as well as that-clauses:

(25) a. Socrates is wise.

b. Socrates is something admirable.

(26) a. John needs a race horse.

b. John needs something expensive.

(27) a. John claimed that S.

b. John claimed something shocking.

Such special quantifiers do not act as ordinary first-order or higher-order quantifiers, but are better regarded as nominalizing quantifiers introducing a 'new' domain of entities into the semantic structure of sentences, entities that would be referents of corresponding nominalizations (wisdom in (25a), the satisfaction of John's need in (26b), and John's claim in (27c)) (Moltmann 2003, 2013b).

Some philosophers have argued that neither reference nor quantification in natural language is existence-entailing and thus ontologically committing. That is because NPs in the role of referential terms and quantifiers appear to be able to stand for merely intentional objects that the speaker considers nonexistent. The relevant examples involve NPs as subjects of negative existentials as well as complements of intentional verbs, as mentioned earlier in the examples (7a) and (8a). This suggests that NPs acting as referential terms and quantifiers are not after all indicative of the ontological commitment of the language, but only NPs of which the existence predicate is true. However, there are in fact a lot of constraints on when NPs are able to stand for merely intentional objects. Their occurrence is restricted to certain predicates such as existence predicates and intentional predicates. Most predicates are existenceentailing, requiring entities considered real by the speaker. That said, the data with negative existentials and intentional verbs indicate that intentional objects, however they may be conceived, form part of the ontology of natural language. Otherwise, the semantics of referential, quantificational, and anaphoric NPs with predicates of existence as well as intentional verbs could hardly be accounted for in a compositional fashion.

The notion of a referential term raises the question whether categories other than noun phrases can play the syntactic role of referential terms. That-clauses are a case in point. While that-clauses do not refer in the way referential NPs do, they have been considered referential terms standing for propositions (Frege 1918/9, Schiffer 2003), though that view is 
controversial (as discussed, for example, in Moltmann 2013b, Chap 4., to appear a) (see Section 7).

Entities may play other roles in the semantic structure of sentences than as semantic values of referential NPs and quantifiers. First of all, they may act as implicit arguments of predicates, as is the case with events on the Davidsonian semantics of verbs and with tropes on an analogous semantics of adjectives. Besides event and trope arguments of verbs and adjectives, other sorts of implicit arguments have been postulated. They include degrees as arguments of adjectives (say heights for tall or degrees of happiness for happy), contextual standards for various sorts of gradable expressions (for example a standard height for tall), and modes of presentations for referential terms in sentences embedded under attitude verbs (and perhaps elsewhere). ${ }^{11}$

As arguments of predicates, degrees, contextual standards, and modes of presentation would have the status of objects, yet the Fregean criterion fails to apply to them, in that, in the core of language, there are not really explicit referential terms able to refer to them, or in fact other ways for ordinary speakers to make them explicit. In fact there is a view, though so far little discussed explicitly, according to which the different ways in which entities are involved in the semantic structure of natural language reflects differences in ontological status, or 'objecthood'. Roughly, on that view, entities for which there are underived nouns enjoy full ontological status (material objects, persons, for example), entities primarily acting as implicit arguments and only derivatively as semantic values of referential terms enjoy only a secondary ontological status (events and tropes), and entities only playing the role of implicit arguments a lesser ontological status yet (degrees, contextual standards, modes of presentation).

There is another important role entities may play in the semantic structure, namely as parameters of contextual evaluation, as part of the context of utterance which serves to identify the meaning of an indexical expression, or as parameters relative to which a sentence is evaluated as true or false. Sometime entities that may act as parameters relevant for evaluation of sentences may also act as semantic values of referential terms. This is the case

\footnotetext{
${ }^{11}$ Modes of presentation roughly, are ways an agent views an object. The semantic need for modes of presentations can be illustrated with a famous example by Kripke. Suppose Pierre visits London on two different occasions, without realizing it is the same city he is visiting. On one occasion London strikes him as pretty, on the other as ugly. In that case, both (ia) and (ib) can be considered true, namely when involving different modes of presentation as part of the semantic value of the embedded sentence:
}

(i) a. Pierre believes that London is pretty.

b. Pierre believes that London is ugly. 
for times, but not so for worlds and situations. Possible worlds and situations have hardly been considered semantic values of referential terms of the core of language. ${ }^{12}$

Possible worlds have played a central role in formal semantics in the tradition deriving from Montague (1973), for the formal construal of linguistic content as well as specifically the semantics of modals and conditionals (Stalnaker 1984). More recently, situations, as partial possible worlds, have been invoked in semantics for various purposes and in various ways: as a replacement of possible worlds for the purpose of obtaining a finer notion of content (Barwise / Perry 1983), as well as the analysis of particular constructions such as perception reports (Barwise/Perry 1983), conditionals and generic sentences (Kratzer 2007/2014), and part-related expressions (Moltmann 1997, 2005). Moreover, situations have been taken to form the domain of certain quantifiers, namely adverbs of quantification such as sometimes or frequently (Berman 1987, Kratzer 2007/2014). In addition, situations have been invoked as reference or resource situations associated with the evaluation of noun phrases, in order to account for the restriction on the domain of quantificational NPs and definite NPs, including pronominal anaphora, on an E-type account on which they stand for definite NPs. ${ }^{13,14}$

\section{Ontological and syntactic categories}

The roles of events in the semantics of verbs and deverbal nominalizations (laughter, walk) and that of tropes in the semantics of adjectives and deadjectival nominalizations (wisdom, happiness) raises the general issue of whether there is a systematic correlation between ontological categories and syntactic categories. Such a correlation would go along with the very old observation that nouns, at least underived ones, are to a great extent associated with substances, whereas adjectives are associated with tropes. In the history of metaphysics as well as linguistics (or 'grammar') such a correlation has sometimes been endorsed (which is

\footnotetext{
12 The noun situation itself is both a technical and non-technical term. In the latter case it imposes particular constraints on spatial continuity, say, that situations as partial worlds of evaluation need not be subject to.

${ }^{13}$ For an overview of the role of situations in semantics see Kratzer (2007/2014).

${ }^{14}$ Situations have yet been invoked for yet another semantic role, namely as truth makers of sentences, in Fine's (to appear b) recent truthmaker semantics. As truthmakers, situations or states, as Fine calls them, are entities wholly relevant for the truth of a sentence, but they do not form the domain of quantifiers or act as referents of referential terms in the language.

Also events and tropes have been posited for the truthmaker role (Moltmann 2007). Even in that role, events and tropes may be conceived as semantic values of expressions such as nominalizations or adverbial modifiers.
} 
why universals that have tropes as instances are also called 'adjectival universals' and universals that have substances as instances 'substantival universals'). ${ }^{15}$ However, one problem is that the correlation is not strict, at least not for nouns, which generally include nouns for all sorts of entities (Szabo 2015). Moreover, the view is challenged by the fact that there are languages that fail to display certain syntactic categories or any syntactic categories at all (Gill 1999). If nonetheless there is a correlation of some sort, it would indicate either that the lexical content of particular syntactic categories reflects the nature of the entities of particular ontological categories or that the syntactic roles of expressions of that category have a semantics that reflects the nature of the ontological category, say as ontologically dependent entities (tropes, events) as opposed to ontologically independent entities (substances).

Another syntactic category distinction that appears to reflect an ontological distinction is the mass-count distinction. In general, count nouns appear to apply to entities that have a boundary or some form of integrity, whereas count nouns apply to quantities, entities that fail to have a boundary or other form of integrity (Moltmann 1997, 1998). There are a range of sell-known exceptions to that generalization, of course. Furniture and police force are mass nouns in English, and amount and quantity are count nouns. Therefore the mass-count distinction may in fact reflect a cognitive distinction or a distinction in perspective rather than an ontological distinction.

One approach to the semantic content of the mass-count distinction characterizes mass nouns and count nouns in terms of extensional mereologcal properties of their extensions (homogeneity, atomicity) (Link 1986), possibly relative to a context (Rothstein 2010). Another approach characterizes the mass-count distinction semantically in terms of a notion of a contextually given and possibly merely conceived integrity (Moltmann 1997, 1998). Yet another approach takes the mass domain to be a pre-individuated domain not consisting of (single) entities at all (Laycock 2006). All the semantic characterizations of the mass-count distinction face an important crosslinguistic challenge in that there are languages (e.g. Chinese) that lack a mass-count distinction and use classifiers instead. See Doetjes (2012) for an overview of the mass-count distinction across languages.

\section{Pleonastic or light objects in the ontology of natural language}

\footnotetext{
${ }^{15}$ This matches the Aristotelian four-category ontology, which was fairly standard in the middle ages and was still recently pursued by Lowe (2006). See also Moltmann (2013b) for a more linguistic discussion.
} 
One important general approach to the wealth of referential terms in natural language is the view that some referential terms involve light entities, entities introduced on the basis of particular sentences or conditions not involving them. One version of that approach is the view that referential terms may stand for pleonastic entities (Schiffer 2003, 2006). Pleonastic entities are entities introduced by particular sorts of inferences, namely inferences from statements not involving the referential term in question to statements involving it, inferences of what Schiffer calls 'something-from-nothing inferences'. The referential term thus stands for an entity introduced by language itself, an entity that has just those properties attributed in virtue of 'something-to-nothing inferences'. Schiffer applies the view to property-denoting terms as well as to what he takes to be proposition-denoting terms, that is, that-clauses, and he takes it to also account for event reference.

Given the pleonastic view, property-denoting terms stand for pleonastic entities introduced by inferences such as from (28a) to $(28 b)$ :

(28) a. Socrates is wise.

b. Socrates has the property of being wise.

Similarly, propositions as semantic values of that-clauses are obtained from inferences such as from (28a) to (28b):

(29) a. It is raining.

b. That it is raining is true.

Pleonastic entities are entities whose only properties are those attributed to them on the basis of inferences as in (28) or (29). Pleonastic entities thus permit a straightforward reduction in the sense of not leading to new truths (truths that could not be stated without reference to those entities).

What is attractive about the pleonastic view is that it preserves the view that referential terms stand for entities while trying to make sense of the derivative, language-related nature of some of those entities. There are a range of challenges, though, associated with the view, which I will only briefly mention. First of all, the view easily overgenerates, since not every 'something-from-nothing' inference should generate a new object.

Second, it is not obvious that all the relevant properties of what are considered pleonastic entities can be obtained by a 'something-from-nothing' inference. For propositions, properties 
not derivable that way include being partially true and being widely believed (both of which cannot be attributed to a proposition as an inference from a sentence not making reference to a proposition as in (29). In fact there are also various sorts of nominalizations that the pleonastic is meant to apply to that allow for predicates that could not be introduced by a something-from-nothing inference. Thus, Socrates wisdom may be deep, admirable, or hard to describe, properties hardly attributable just as a matter of an inference from a sentence not making reference to Socrates' wisdom. In fact, the pleonastic account is inapplicable to tropes, attitudinal objects, and events, which are concrete, fully specific entities whose nature is not fixed by inferences introducing terms for them (Moltmann 2007, 2013b Chap 1).

Another issue is that the pleonastic account is restricted to terms that are, in one way or another, syntactically or morphologically derived from an expression that can figure in sentences in which no reference to the entity in question is made. This is the case for nominalizations, that-clauses as well as complex terms of the sort the property of wisdom. However, this is not always the case, for example not for events, to which the view is also meant to apply. For events, the view would exploit the alternation between adverbial constructions as in (30a), premises of 'something-from-nothing'-inferences, and sentences in which the same expression acts as a predicate, as in (30b):

(30) a. John walked slowly.

b. John's walk was slow.

However, events are not always tied to deverbal nominalization (fire, war, incident etc).: ${ }^{16}$ While the pleonastic account may not systematically apply to nominalizations that stand for abstract or minor entities, it appears to have particular plausibility for reifying terms as in (22) and (23), as complex terms introducing entities on the basis of a nonreferential expression with which they are formed (Moltmann 2013b, Chap. 6).

Somewhat related to the theory of pleonastic entities is the view that some referential terms stand for entities obtained by abstraction in the Fregean sense (Frege 1884, Wright 1983, Hale 1987). ${ }^{17}$ Again this is a view according to which certain terms stand for entities

\footnotetext{
${ }^{16}$ A different version of the pleonastic account has been developed by Thomasson (2014), with an application to ordinary objects. That account would not be restricted to derived terms and permits a greater range of predicate applying to the newly introduced term.

${ }^{17}$ Also somewhat related is the view according to which certain referential terms and quantifiers do not stand for objects but play only a role in inferences, for the purpose of conveying focus-related information (Hofweber 2007).
} 
whose intrinsic properties are determined by the method of their introduction. The abstractionist account is best known from Frege's introduction of natural numbers on the basis of equinumerous concepts. However, Kim's (1976) account of events is in fact of the very same nature (Moltmann 2013c). Kim's account consists in giving existence and identity conditions for an event $[\mathrm{d}, \mathrm{P}, \mathrm{t}]$ obtained from an object $\mathrm{d}$, a property $\mathrm{P}$, and a time t:

(32) For individuals d, d', properties P, P', and times t, t',

[1] [d, P, t] exists iff $\mathrm{P}$ holds of $\mathrm{d}$ at $\mathrm{t}$.

$[2][d, P, t]=\left[d^{\prime}, P^{\prime}, t^{\prime}\right]$ iff $d=d^{\prime}, P=P^{\prime}, t=t^{\prime}$.

Since on that account, events have no other intrinsic properties that what is specified by their method of introduction, (32) does not permit events to have causal roles, a spatial location, or a specific manifestation. For such reasons, it is generally agreed that Kim's account captures (nonworldly) facts rather events.

Kim's account may have an additional application besides to facts, namely to the implicit Davidsonian arguments of certain stative verbs. Stative verbs such as own, know, believe, and weigh, it has been argued, take 'Kimean' or 'abstract' states as arguments, entities on a par with nonwordly facts (Maienborn 2007, Moltmann 2013c). Unlike the pleonastic account, the abstractionist account does not impose conditions on the form of the relevant referential term and the contexts in which the term may occur. Thus, it permits implicit arguments of predicates to be entities obtained by abstraction in the way of (32).

\section{The importance of natural language ontology}

Why should natural language ontology be pursued? What is gained by uncovering the ontological categories and structures reflected in natural language? These questions will be raised particularly by philosophers who reject the types of entities seemingly reflected in natural language, in favor of what are considered more fundamental categories of entities, categories that are supposed to make up reality and are the only ones needed in a full description of the world.

There are not only good reasons to pursue the project of natural language ontology for its own sake, there are also grounds to doubt that foundational metaphysics can be pursued entirely independently of the ontology reflected in natural language. As Fine (to appear a) has emphasized, it is important to establish what exactly it is that needs to be accounted for in 
more fundamental terms if foundational metaphysics is being pursued. Natural language ontology can be viewed a systematic pursuit of descriptive ontology in the sense of Strawson (1959), as the project that aims to uncover the ontology we implicitly accept. But rather than taking as the basis of that project the judgments that are part of a shared conceptual scheme (and a few linguistic examples here and there), natural language ontology takes as its basis linguistically reflected intuitions by making full use of the methods and established generalizations of linguistic semantics and its interface with syntax. For a range of issues in metaphysics, the linguistic reflections may just be the best indication of how we, implicitly, conceive of things.

Many philosophers dismiss natural language as a good basis for pursuing metaphysics because they take it to be obvious that natural language involves too rich and problematic an ontology, say a rich ontology of abstract objects, with terms referring to properties, propositions, numbers, and degrees. Also in regard to such an attitude, the pursuit of natural language ontology has an important task, namely the investigation and clarification what ontological categories, notions, and structures natural language actually involves. This is important because the ontology of natural language often turns out to be quite different from what philosophers take it to be.

Here are some examples of such a discrepancy. One of them concerns the rich ontology of abstract objects that natural language is supposed to display, an ontology supposedly including in its core such entities as properties, propositions, numbers, and degrees. This view of the ontology of natural language picture may be fundamentally mistaken. Thus, I have argued in Moltmann (2013b) that natural language is much more particularist, involving in its core no reference to abstract objects. Instead it involves reference to a great range of different sorts of tropes or trope-related entities or else to kinds of tropes, entities such as 'wisdom' or 'happiness'. Kinds (semantic values of bare plurals and mass nouns) are themselves considered pluralities of (possible or actual) particulars. Thus, instead of referring to an abstract object that is a property, the bare mass noun wisdom, stands for the plurality of all the particular wisdom manifestations. Moreover, instead of referring to a number as an abstract object, the number of planets refers to a number trope, the instantiation of the property of being eight in the plurality of the planets. Instead of referring to a degree, the extent of John's anger refers to a quantitative trope etc. Only in the periphery of language, with complex, quasi-technical terms involving sortals for abstract objects such as the property of being wise, 
the number eight, and the degree of John's anger, does natural language permit reference to abstract objects, such as properties, numbers, and degrees. ${ }^{18}$

Another important case of a discrepancy between the ontology philosophers take natural language to involve and the one it arguably really reflects concerns propositions (Moltmann 2003, 2013b). Many philosophers (and linguists) take it for granted that that-clauses in the complement position of attitude verbs are referential terms and as such stand for propositions, the abstract meanings of sentences (Stalnaker 1984, Schiffer 2003). Propositions, on that view, will then act as arguments of a two place-attitudinal relation between agents and propositions and thus serve as the contents or objects of attitudes. However, linguistically, it is in fact far from obvious that that-clauses act as referential terms, one reason being that thatclause do not generally permit a replacement by an explicit proposition-referring term even when the attitude verbs accepts NPs as complements (while John thought that S and John thought something are acceptable, John thought the proposition that $\mathrm{S}$ is not). Moreover, natural languages in their core generally lack explicit proposition-referring terms. Terms of the sort John thought that S, John's belief that S, or John's promise that S certainly are part of the core of English, but they have a range of properties not shared by propositions and are better taken to stand for entities of a different sort - 'products' (Twardowski 1911) or better 'attitudinal objects' (Moltmann 2003, 2013b Chap. 4, to appear a).

Such discrepancies show how important it is to first clarify what sort of ontology natural language actually involves before rejecting it.

The ontology that natural language reflects is a subject matter that is of interest also in itself. It goes along with way we implicitly conceive of certain general aspects of the world and it reflects, at least in part, our cognitive faculty. In addition the ontology of natural language may provide answers to a range of philosophical issues, not just as part of a particular descriptive metaphysical approach to them. This may be so particularly regarding the nature of propositional attitudes and the semantics of attitude reports, where natural language appears to display a much less familiar ontology of attitudinal objects given standard ontological views.

Of course, the ontological structures that natural language displays need not be the right one and certain not the fundamental ones. But it is important to find out what they are before rejecting natural language as a guide to ontology.

\footnotetext{
${ }^{18}$ In fact, even that picture is simplified. The category of tropes reflected in natural language turns out to be considerably richer than the category philosophers generally make reference to, for example by distinguishing a quantitative trope such as John's height from a trope that is John's tallness, and a trope that is John's strength from a trope that is John's weakness (Moltmann 2009, 2013b).
} 


\section{Further issues}

Natural language ontology raises very particular issues that do not as such arise with metaphysics pursued in a context of purely philosophical interests.

Most importantly, the ontology of natural language may be driven in part by requirements of the use of language, rather than just how things are or rather how they are conceived to be. In fact, there are some theoretical developments in semantics that aim at a part of ontology that is specifically language- or discourse-driven.

One such development was already mentioned, namely the theory of pleonastic entities, which takes certain natural language terms to have the role of introducing entities by way of inferences from statements not involving them.

An example of a discourse-related quasi-ontological notion is that of a discourse referent outlined in Karttunen (1976), a notion that gave rise to subsequent developments of dynamic semantics. Discourse referents, as Karttunen describes it, are introduced by unbound anaphoric pronouns such as he below, which will stand for a discourse referent, an entity partially specified only as a man and having sat down (in relevant circumstances):

(33) A man might come in. He might sit down.

Discourse referents have been attributed a quasi-ontological status as objects, even if individuated just by the flow of information in the discourse, by Landmann (1986). However, later development of dynamic semantics generally do not adhere to a (quasi-) ontological view of discourse referents, but take them to be representations in a discourse representation structure (Kamp 1981), or else complex semantic values partly composed of actual objects (in circumstances) (Heim 1982 and subsequent work).

Entities somewhat like discourse referents have been posited also for the semantics of sentences involving intentional identity, as below:

(34) John thinks that student broke in. Mary thinks that he stole her book.

Again the intentional objects posited here have been taken to be individuated by the flow of information in the discourse, not just the attitudes of the described agents (Edelberg 1986). 
Another theoretical development in semantics that argues for a discourse-driven part of ontology is the theory of parts and wholes of Moltmann $(1997,2005)$. The view pursued there is that the pluralities and quantities involve a part-whole structure based not only on a partwhole relation among entities, but also the notion of an integrated whole. This, so the view, they share with individuals, which themselves typically are intrinsic integrated wholes. Unlike individuals, pluralities and quantities generally have a part-whole structure that depends on information given in the discourse, in particular the information content of the terms used to refer to them. Thus it will depend on whether a quantity of gold is described as consisting of maximal subquantities sharing a property or relating to another object whether a predicate like compare is applicable:

(35) a. ??? John compared the gold.

b. John compared the gold in the different boxes.

c. John compared the gold of the three rings.

Compare requires an argument that consists of integrated wholes but is not itself an integrated whole in the situation of reference. This condition may be fulfilled by pluralities or else quantities consisting of parts that have been described as maximal subquantities sharing a property or relating to another object. This means it is a condition to be fulfilled by an information-driven part structure. The notion of such an information-based situated part structure is, on that view, central for the semantics of part-structure-sensitive predicates such as compare as well as part-structure-sensitive modifiers such as individual and whole (as in the individual students and the whole collection). The semantically relevant part structures of pluralities and quantities thus are those they have in the situation of reference, which is largely driven by the information given by the expressions used and well as the contribution of part structure modifiers such as individual and whole.

Another issue that natural language ontology specifically raises is the question of the crosslinguistic validity of ontological generalizations that may have been made on the basis of a particular language. In this regard, two things can be said.

First of all, crosslinguistic research in semantics as such is only a very recent development. Semantics until recently had restricted itself to English or some other European languages. Crosslinguistic work on ontological topics, in particular; had hardly been pursued.

Second, there should be good reasons to assume that ontological categories, notions, and structures are universal. Certainly, if the ontology of natural language is based on a shared 
cognitive faculty, there would be the very same reason to assume that it is universal as there are to assume that human languages are based on a shared universal grammar, a core assumption of generative linguistics. As in generative syntax, it certainly is reasonable and fruitful to pursue the view that a deeper analysis of different languages will reveal universal features of the ontology of natural language - just as a deeper analysis of English, as was mentioned, generally reveals a different ontological structure than what philosophers generally thought natural language involves While a particular language may not display a particular category of objects in its terms, predicates or operators, it is reasonable to assume that the categories a language may display come from a universal inventory that is part of our cognitive ontology or perhaps a shared number of ontological operations that may generate them.

\section{Further Readings}

Fine, K. (2003): ‘The Non-Identity of a Material Thing and Its Matter'. Mind 112,195 - 234.

-------- (2006): 'In Defense of Three-Dimensionalism'. Journal of Philosophy 103 (12) 699714.

Moltmann, F. (1997): Parts and Wholes in Semantics. Oxford UP, New York, (2013a): Abstract Objects and the Semantics of Natural Language. Oxford UP,

Oxford. (2013b): 'The Semantics of Existence'. Linguistics and Philosophy 36.1., 31-63.

Woltersdorff, N. (1970): On Universals. Chicago UP, Chicago.

Vendler, Z. (1967): Linguistics in Philosophy. Cornell University Press, Ithaca, NY. (1972): Res Cogitans. Cornell UP, Ithaca, NY.

\section{Acknowledgment}

I would like to thank two anonymous referees, Kit Fine and Jim Pryor for discussion and comments on a previous version of this paper. The paper has also benefitted greatly from the audiences at the University of Milan and the conference Formal Ontology in Information Systems (FOIS) (Annecy 2016), especially Nicola Guarino, Giuliano Torrengo, Paolo Valore, and Laure Vieu

\section{References}


Asher, N. (1993): Reference to Abstract Objects. Kluwer Academic Publishers, Dordrecht. Bach, E. (1986): 'Natural Language Metaphysics'. In R. Barcan Marcus et al. (eds): Logic, Methodology, and Philosophy of Science VI, North Holland, Amsterdam et al., 573-595.

Barwise, J. / J. Perry (1983): Situations and Attitudes. MIT Press, Cambridge (Mass.).

Berman, S. (1987): 'Situation-Based Semantics for Adverbs of Quantification',

J. Blevins and A. Vainikka (eds.): University of Massachusetts Occasional Papers 12, Amherst.

Campbell, K. (1990): Abstract Particulars. Blackwell, Oxford.

Chao, W. / Bach, E. (2012): 'The Metaphysics of Natural Language(s).' In Kempson et al. (eds.): Philosophy of Linguistics, 14. North Holland, Elsevier, Amsterdam, 175-196.

Chierchia G. / R. Turner (1988): 'Semantics and Property Theory'. Linguistics and Philosophy 11, 261-302

Chomsky, N. (1986): Knowledge of Language. Its Nature, Origin, and Use. Praeger, Westport $(\mathrm{Ct})$ and London.

Cresswell, M. J. (1977): 'The Semantics of Degree'. In B. Partee (ed.): Montague Grammar, Academic Press, New York, 261-292. (1986): 'Why Object Exists, but Events Occur'. Studia Logica 45, 371-5.

Davidson, D. (1967): 'The Logical Form of Action Sentences'. In N. Rescher (ed.): The Logic of Decision and Action. Pittsburgh UP, Pittsburgh, 81-95.

Den Dikken, M. / A. Meinunger / C. Wilder (2000): 'Pseudclefts and Ellipsis'. Studia Linguistica 54, 41-89.

Doetjes J.S. (2012): ‘Count/Mass Distinctions across Languages'. In C. Maienborn / K. von Heusinger / P. Portner (eds.): Semantics: An International Handbook of Natural Language Meaning, Part III. De Gruyter, de Gruyter, 2559-2580.

Edelberg, W. (1986): ‘A New Puzzle about Intentional Identity’. Journal of Philosophical Logic 15, 1-25 (1986).

Fine, K. (1982a): ‘The Problem of Non-Existents. I. Internalism.” Topoi, 1: 97-140. - (1982b): 'First-Order Modal Theories III - Facts',Synthese 53, 293-308. (2003): 'The Non-Identity of a Material Thing and Its Matter'. Mind 112,195 - 234. (2006): 'In Defense of Three-Dimensionalism'. Journal of Philosophy103 (12), 699714. (to appear a): 'Naïve Metaphysics', ms NYU. (to appear b): 'Truthmaker Semantics'. In B. Hale / C. Wright (eds.): Blackwell 
Philosophy of Language Handbook. Blackwell, New York.

Frege, G. (1884): Die Grundlagen der Arithmetik ('Foundations of Arithmetic') (1892): 'Funktion und Begriff'. Reprinted in G. Patzig (ed.): Funktion, Begriff,

Bedeutung, Vandenhoeck and Ruprecht, Goettingen.

(1918/9): 'Thoughts'. In Collected Papers on Mathematics, Logic, and Philosophy, ed. by B. McGuinness. Blackwell, Oxford, 1984, 351-372.

Gil, D. (1999): 'Syntactic Categories, Cross-linguistic Variation and Universal Grammar'. In

P. Vogel / B. Comrie (eds.): Approaches to the Typology of Word Classes. (Empirical Approaches to Language Typology 23). New York: Mouton de Gruyter. 173-216.

Hacker, P. M. S. (1982): 'Events, Ontology, and Grammar'. Philosophy 57, 477-486.

Hale, B. (1987): Abstract Objects. Blackwell, Oxford.

Higgins, F. R. (1973): The Pseudo-Cleft Construction in English. Indiana University Linguistics Club.

Hofweber, T. (2007): 'Innocent Statements and their Metaphysically Loaded Counterparts'. The Philosophers' Imprint, Vol. 7 no. 1, 1-33.

Van Inwagen, P. (2001): 'Existence, Ontological Commitment, and Fictional Entities'. M. Loux / D. Zimmerman (eds.): The Oxford Handbook of Metaphysics. Oxford UP, Oxford. Jacobson, P. (1994): 'Binding Connectivity in Copula Sentences'. In M. Hary / L. Satelman (eds.): Proceedings of SALT 7, CLC Publications, Ithaca, NY, 161-178.

Karttunen, L. (1976): 'Discourse Referents'. In J. D. McCawley (ed.): Syntax and Semantics, Vol.7. Academic Press, New York, 363 - 386.

Kim, J. (1976): 'Events as Property Exemplifications'. In M. Brand / D. Walton (eds.): Action Theory. Reidel, Dordrecht, 310-326.

King, J. (2006): 'Semantics for Monists'. Mind 115, 1023-1058

Kratzer, A. (2007/2014): 'Situations in Natural Language Semantics'. Stanford Encyclopedia of Philosophy. Online.

Landman, F. (1986): 'Pegs and Alecs'. In F. Landman: Towards a Theory of Information. The Status of Partial Objects in Semantics, GRASS 6, Foris, Dordrecht, 97-155.

Laycock, H. (2006): Words without Objects: Semantics, Ontology, and Logic for NonSingularity. Oxford University Press.

Link, G. (1983): 'The Logical Analysis of Plurals and Mass Nouns'. In R. Baeuerle et al. (eds.): Semantics from Different Points of View. Springer, Berlin, 302-323.

Lowe, J. (2006): The Four-Category Ontology. A Metaphysics Foundation for Natural Science. Oxford UP. 
Magidor, O. (2013): Category Mistakes. Oxford UP, Oxford.

Maienborn, C. (2007): 'On Davidsonian and Kimian States'. In I. Comorovski / K. von Heusinger (eds.): Existence: Semantics and Syntax. Springer, 107-130.

Moltmann, F. (1997): Parts and Wholes in Semantics. Oxford UP, New York, (1998): 'Part Structures, Integrity and the Mass-Count Distinction'. Synthese 70, 1998, 75-111.

(2003): 'Nominalizing Quantifiers'. Journal of Philosophical Logic.35.5., 445-481.

(2004a): 'Properties and Kinds of Tropes: New Linguistic Facts and Old Philosophical Insights'. Mind 123.1., 2004, pp. 1-41.

(2004b): 'Two Kinds of Universals and Two Kinds of Collections'. Linguistics and Philosophy 27.6., 2004, pp. 739-776.

(2005): 'Part Structures in Situations: The Semantics of Individual and Whole'. Linguistics and Philosophy, 28.5., 2005, pp. 599-641.

(2007): 'Events, Tropes and Truthmaking'. Philosophical Studies 134,

363-403.

(2009): 'Degree Structure as Trope Structure: A Trope-Based Analysis of

Comparative and Positive Adjectives'. Linguistics and Philosophy 32, 51-94.

(2013a): 'Reference to Numbers in Natural Language'. Philosophical Studies

162.3., pp. 499-534.

(2013b): Abstract Objects and the Semantics of Natural Language. Oxford UP,

Oxford.

(2013c): 'On the Distinction between Abstract States, Concrete States, and

Tropes'. In C. Beyssade, A. Mari, F. Del Prete (eds.): Genericity, Oxford UP, Oxford, 292-311

(2013d):'The Semantics of Existence'. Linguistics and Philosophy 36.1., 31-63.

- (2014a):'Propositions, Attitudinal Objects, and the Distinction between Actions and Products'. Canadian Journal of Philosophy 43.5-6, 679-701.

(2014b): 'Parts, Wholes, Abstracts, Tropes and Ontology'. 3am interview with

Richard Marshall, Feb. 14, 2014,

http://www.3ammagazine.com/3am/parts-wholes- abstracts-tropes-and-ontology/

(2016a): 'Quantification with Intentional and with Intensional Verbs'. In

A. Torza (ed.): Quantifiers, Quantifiers, Quantifiers. Synthese Library, Dordrecht. (2016b): 'Plural Reference and Reference to a Plurality. Linguistic Facts and 
Semantic Analyses'. In M. Carrara / A. Arapinis / F. Moltmann (eds.): Unity and Plurality.

Philosophy, Logic, and Semantics. Oxford University Press, 93-120.

(to appear a): 'Cognitive Products and the Semantics and Attitude Verbs and

Deontic Modals'. In F. Moltmann / M. Textor (eds.): Act-Based Conceptions of

Propositional Content, Oxford UP, New York.

(to appear b): 'Variable Objects and Truthmaking'. To appear in M. Dumitru

(ed.): The Philosophy of Kit Fine, Oxford UP, New York.

Montague, R. (1973): 'The Proper Treatment of Quantification in Ordinary English'. In J.

Hintikka et al. (eds.): Approaches to Natural Language. Reidel, Dordrecht.

Oliver, A. / T. Smiley (2013): Plural Logic. Oxford UP. Oxford.

Parsons, T. (1980): Nonexistent Objects. Yale UP, New Haven.

Priest, G. (2005): Towards Nonbeing. Oxford UP, Oxford.

Pryor, J. (2007): 'Reasons and That-Clauses'. Philosophical Issues 17 (1), 217-244.

Quine, W. V. (1948): 'On What There Is'. The Review of Metaphysics 2(1): 21-38, reprinted

in W. V. Quine: From a Logical Point of View, Harper, New York, 1953: 1-19.

Romero, M. (2005): 'Concealed Questions and Specificational Subjects'. Linguistics and Philosophy 25, 687-737.

Rothstein, S. (2010): 'Counting and the Mass-Count Distinction'. Journal of Semantics 27 (3), 343-397.

Salmon, N. (1987): 'Existence'. Philosophical Perspectives 1, 49-108. (1998): 'Nonexistence'. Nous 32.3., 277-319.

Schiffer, S. (1996): 'Language-Created and Language-Independent entities'. Philosophical Topics 24.1., 149-167.

(2003): The Things We Mean. Clarendon Press, Oxford.

Sider, T. (2006): 'Quantifers and Temporal Ontology'. Mind 115, 75-97

Stalnaker, R. (1984): Inquiry. MIT Press, Cambridge.

Strawson, P. (1959): Individuals. An Essay in Descriptive Metaphysics. Methuen, London.

Swanson, E. (2012): 'The Language of Causation'. In D. Graff Fara / G. Russell (eds.):

The Routledge Companion to the Philosophy of Language, Routledge, London, 716-728.

Szabo, Z. (2007): 'Counting Across Times'. Philosophical Perspectives 20: Metaphysics, $399-426$.

(2015): 'Major Parts of Speech'. Erkenntnis 80, 3-29.

Thomasson, A. (2014): Ontology Made Easy. Oxford UP, Oxford. 
Twardowski, K. (1912): 'Actions and Products. Some Remarks on the Borderline of Psychology, Grammar, and Logic'. In J. Brandl / J. Wolenski (eds.): Kazimierz Twardowski. On Actions, Products, and Other Topics in the Philosophy. Rodopi, Amsterdam and Atlanta, 1999, 103-132.

Vendler, Z. (1967): Linguistics in Philosophy. Cornell University Press, Ithaca, NY. (1972): Res Cogitans. Cornell UP, Ithaca, NY.

Williams, D. C. (1953): 'On the Elements of Being'. Review of Metaphysics 7, 3-18.

Woltersdorff, N. (1970): On Universals. Chicago UP, Chicago.

Wright, C. (1983): Frege's Conception of Numbers as Objects. Aberdeen UP, Aberdeen.

Yi, B.-Y. (2005): 'The Logic and Meaning of Plurals. Part I'. Journal of Philosophical Logic 34, 459-506.

(2006): 'The Logic and Meaning of Plurals. Part II'. Journal of Philosophical Logic 35, 239-288.

Zucchi, S. (1983): The Language of Propositions and Events. Springer, Dordrecht. 